\title{
Electrocardiogram recordings in free-ranging gannets reveal minimum difference in heart rate during flapping versus gliding flight
}

\author{
Yan Ropert-Coudert ${ }^{1, *}$, Rory P. Wilson ${ }^{2}$, David Grémillet ${ }^{3}$, Akiko Kato ${ }^{1}$, Sue Lewis ${ }^{4}$, \\ Peter G. Ryan ${ }^{5}$ \\ ${ }^{1}$ National Institute of Polar Research 1-9-10 Kaga, Itabashi-ku, Tokyo 173-8515, Japan \\ ${ }^{2}$ School of Biological Sciences, University of Wales-Swansea, Singleton Park, Swansea SA2 8PP, UK \\ ${ }^{3}$ Centre National de la Recherche Scientifique, Département d'Ecologie, Physiologie et Ethologie, Institut Pluridisciplinaire \\ Hubert Curien, 23 rue Becquerel, 67087 Strasbourg Cedex 02, France \\ ${ }^{4}$ Centre for Ecology and Hydrology, Banchory Research Station, Hill of Brathens, Banchory, Aberdeenshire AB31 4BW, UK \\ ${ }^{5}$ DST/NRF Centre of Excellence at the Percy FitzPatrick Institute, University of Cape Town, Rondebosch 7701, South Africa
}

\begin{abstract}
Gliding flight is one of the major features that allows flying animals to cover extensive distances while minimising their energy expenditures. This has been supported by studies recording heart rate as a proxy for energy expended, but the exact amount of flapping and gliding during flight is often not taken into account, making a genuine assessment of the heart rate evolution with flight modes problematic. We used miniature accelerometers and electrocardiogram recorders attached externally to free-ranging Cape gannets Morus capensis to examine how heart rate varies when birds use gliding or flapping flight. Flapping phases (in beats per minute; $255.5 \mathrm{bpm}$ ) showed consistently higher heart rates than gliding phases $(217.2 \mathrm{bpm})$, with the changes in heart rate at the onset of a new phase (flapping or gliding) being almost instantaneous, irrespective of the duration of the subsequent phase. Surprisingly though, the difference between the heart rates measured during flapping and gliding flights only amounted to about $20 \%$. Such a small difference does not accord with the fact that gannets are known to have elevated flight costs. This discrepancy suggests that heart rate and metabolic rate are not correlated linearly in M. capensis. Cardio-vascular adjustments, such as a variable stroke volume (following Fick's law), might have evolved because local wind conditions and gannet foraging strategies are not always compatible with gliding flight.
\end{abstract}

KEY WORDS: Heart rate - Locomotion - Externally attached data-logger - Flap and glide flight · Sulidae $\cdot$ Morus capensis $\cdot$ Bio-logging

\section{INTRODUCTION}

All species have evolved anatomical, physiological and behavioural strategies to increase the efficiency of locomotion. Among all possible travel modes, flight has the highest costs per unit time, so it is no surprise that several volant animals (mammals, birds, insects) display common tactics to reduce the costs of being airborne. For instance, gliding flight is considered to be an extremely energetically efficient method of trans- port (Norberg 1986). Together with soaring flight (Pennycuick 2002), gliding is a fundamental feature allowing many long-range flying animals, such as procellariiform seabirds, to breed successfully while exploiting distant, patchy food resources (Pennycuick 1982). Typically, albatrosses represent the most striking examples of long-range foragers that rely on gliding flight to reduce their travelling costs. The wandering albatross Diomedea exulans, when foraging for chicks, may fly at speeds in excess of $80 \mathrm{~km} \mathrm{~h}^{-1}$, cover- 
ing up to $900 \mathrm{~km} \mathrm{~d}^{-1}$ (Jouventin \& Weimerskirch 1990). Despite this remarkable performance, the field metabolic rate (FMR) of these birds, as measured by doubly labelled water (Nagy et al. 1999), is only ca. 1.4 to 2.0 times that of the birds at rest (Pennycuick 1982, Weimerskirch et al. 2000, Shaffer et al. 2001), indicating extreme efficiency during flight. By contrast, seabirds that habitually fly by flapping, such as the great cormorant Phalacrocorax carbo, have flight costs estimated to be about 6.5 to 8 times their resting metabolic rate, e.g. $97.7 \mathrm{~W}$ (Pennycuick 1989) versus 11.9 to 14.8 W (Grémillet \& Wilson 1999, Storch et al. 1999), although there is a good deal of interspecific variance (cf. Pennycuick 1987). The amount of flapping seems to be a prime factor that determines the metabolic cost of flight, since it has been shown that northern gannets Morus bassanus flap more and consequently have a higher FMR (Birt-Friesen et al. 1989) than the closely related red-footed boobies Sula sula (Ballance 1995) that glide more often. Within a single species, Furness \& Bryant (1996) showed that northern fulmars Fulmarus glacialis expend more energy when unable to glide effectively if they have to fly during periods of reduced wind speeds.

The low energetic cost of flight in seabirds has been supported by studies using animal-associated loggers to monitor heart rate (Butler \& Woakes 1979), because, following extensive work on a variety of birds ranging from barnacle geese Branca leucopsis and blackbrowed albatrosses Thalassarche melanophrys to Gentoo penguins Pygoscelis papua, heart rate has been found to be closely and linearly correlated to energy expenditure (e.g. Nolet et al. 1992, Green et al. 2001, Weimerskirch et al. 2002). Weimerskirch et al. (2000) noted that wandering albatross heart rates during flight were sometimes as low as those of the birds resting on the water surface, and Bevan et al. (1995) reported that the value for black-browed albatrosses was 2 times that on land, implying that energy expenditure was similarly scaled. The difficulty with these studies is, however, that the precise relationship between heart rate and energy expenditure is not known, and, although the values are supposed to scale linearly (see references above), some studies have demonstrated that the gradient of heart rate against energy expenditure varies according to activity (Froget et al. 2002, Ward et al. 2002, McPhee et al. 2003). In particular, the precise amount of time spent in flapping flight by birds is not factored into the calculations, making a genuine assessment of the costs of flapping versus gliding flight problematic.

Recent advances in solid-state technology (see Ropert-Coudert \& Wilson 2005) have made it possible to examine both the activity of seabirds (e.g. RopertCoudert et al. 2004) and their heart rate (e.g. Kuroki et al. 1999) with exceptional temporal resolution so that, theoretically, heart rate can be correlated with activity. We used accelerometers and electrocardiogram recorders attached to free-ranging Cape gannets Morus capensis in logging systems to determine how heart rate varies as a function of the degree to which the birds divide their time into gliding and flapping flight. Cape gannets are good models to examine this question because they routinely alternate between bouts of flapping and gliding flight (Ropert-Coudert et al. 2004). In common with many other studies on heart rate (see above) we cannot convert heart rate into energy expenditures. However, we discuss our results in the light of what is known of the relationship between these 2 currencies.

\section{MATERIALS AND METHODS}

The study took place at Cape gannet Morus capensis breeding colonies on Malgas Island (Saldanha Bay, $33^{\circ} 3^{\prime} \mathrm{S}, 17^{\circ} 55^{\prime} \mathrm{E}$ ) and Bird Island, Lambert's Bay $\left(32^{\circ} 5^{\prime} \mathrm{S}, 18^{\circ} 18^{\prime} \mathrm{E}\right)$, South Africa, during November to December 2003. Eight birds were simultaneously equipped with an accelerometer and an electrocardiogram (ECG) recorder. Heart rate was recorded using a miniaturised, cylindrical ECG recorder sampling at $500 \mathrm{~Hz}$ (UWE-380-ECG, 12 bit resolution, $105 \times 20 \mathrm{~mm}$, $52 \mathrm{~g}$, Little Leonardo). Three 5 to $7 \mathrm{~cm}$ cables $(1 \mathrm{~mm}$ diameter) emerged from the logger and ended with a $2 \mathrm{~cm}$, needle-shaped electrode, soldered to the cable. The logger recorded the voltage between 2 electrodes at a range of -5.9 to $+5.9 \mathrm{mV}$, with $2.88 \times 10^{-3} \mathrm{mV}$ resolution in an $8 \mathrm{MB}$ flash memory. The last electrode was the Earth electrode, used to reduce the noise. The efficiency of this type of data logger to detect the ECG of seabirds has been demonstrated on 2 captive hens Gallus domesticus and 4 free-ranging Adélie penguins Pygoscelis adeliae (Kuroki et al. 1999), as well as on great cormorants (Yamamoto 2001). We also checked the reliability of the signal recorded by the logger using an ECG monitor (HeartMate, IEC-1103, NihonKoden) on a captive Cape gannet. The pulses recorded by the monitor and the logger were identical.

Gannet activity was measured using a cylindrical, 4 channel data logger (M190-D2GT, 12 bit resolution, $53 \times 15 \mathrm{~mm}, 17 \mathrm{~g}$, Little Leonardo), which simultaneously monitored depth (sampling frequency: $1 \mathrm{~Hz}$ ) and acceleration along 2 axes (sampling frequency: $16 \mathrm{~Hz}$ on each axis): surging along the longitudinal axis of the birds and heaving along the dorso-ventral axis (see Ropert-Coudert et al. 2004). We used a start timer to delay the onset of the recording so that the ECG logger started to monitor $2 \mathrm{~h}$ after deployment to account for the time spent on land by birds, preening and mixing 
with other individuals, before starting their foraging trip. The accelerometers recorded without interruption from deployment up to $4.5 \mathrm{~d}$.

The departing bird in a gannet pair (i.e. the individual adopting a 'sky-pointing' posture; Nelson 1978) was captured near its nest or at the periphery of the colony using a short crook. An acceleration logger was attached with 3 strips of waterproof Tesa ${ }^{\circledR}$ tape to the underside of the 3 central tail feathers, parallel to their main axis. The body of the ECG logger was then attached on the upper side of the same 3 feathers with Tesa ${ }^{\circledR}$ tape (Fig. 1). Three soft plastic cables emerged from the head of the ECG logger; they ended in safety pins that were attached sub-cutaneously to 3 different points on the bird's lower back near the tail and covered with a piece of Tesa ${ }^{\circledR}$ tape. Prior to electrode attachment, the feathers around the point of insertion were removed and the skin was disinfected with $70 \%$ alcohol. The use of Tesa ${ }^{\circledR}$ tape allowed us to minimise the damage that logger attachment may cause to the bird's feathers (Wilson et al. 1997) and to reduce the handling time. Attaching the equipment took 10 to $20 \mathrm{~min}$. Attachments were always performed in a shaded place to prevent the birds from overheating. The package accounted for 2.3 to $2.8 \%$ of the birds' body masses, which is well below the $5 \%$ threshold beyond which behavioural disruptions are likely to occur in flying seabirds (Croll et al. 1992) and just under the recently revised 3\% threshold (Phillips et al. 2003). Following release, birds joined groups of departing birds and were observed until they flew off. After a foraging trip, the birds were recaptured on their nest and both loggers were removed. Subsequently, the behaviour of the instrumented birds was followed as long as permitted by the investigators' dates of presence on the colony of Malgas and Lambert's Bay. No experimental bird abandoned its chick following the experiment, but we could not verify that the breeding success of equipped birds differed from that of non-equipped birds because we had to leave the islands before the chicks fledged. However, all individuals appeared to behave normally both when equipped with the logger and following the removal of the loggers (e.g. we did not observe extensive preening periods that could have indicated that birds were hampered by the loggers). A previous study using data loggers of similar size attached to Cape gannets in the same manner also indicated that the birds were not handicapped during the trials (Grémillet et al. 2004).

Following recovery, data were downloaded onto a computer and analysed using Igor pro (Wavemetrics v. 4.01). Wing beats were apparent in the acceleration signals as an oscillating pattern present on both axes simultaneously (Fig. 2), with each propulsive stroke recorded on the heaving axis, resulting in a forward acceleration recorded on the surging axis. To confirm that the oscillating patterns corresponded to flapping flight, we video-monitored the instrumented birds upon their take-off from the island and tracked them as long as we could. Following recovery of the logger, we matched the video data to the signals recorded by the loggers (Ropert-Coudert et al. 2004). This oscillating pattern has also been identified as an accurate repre-
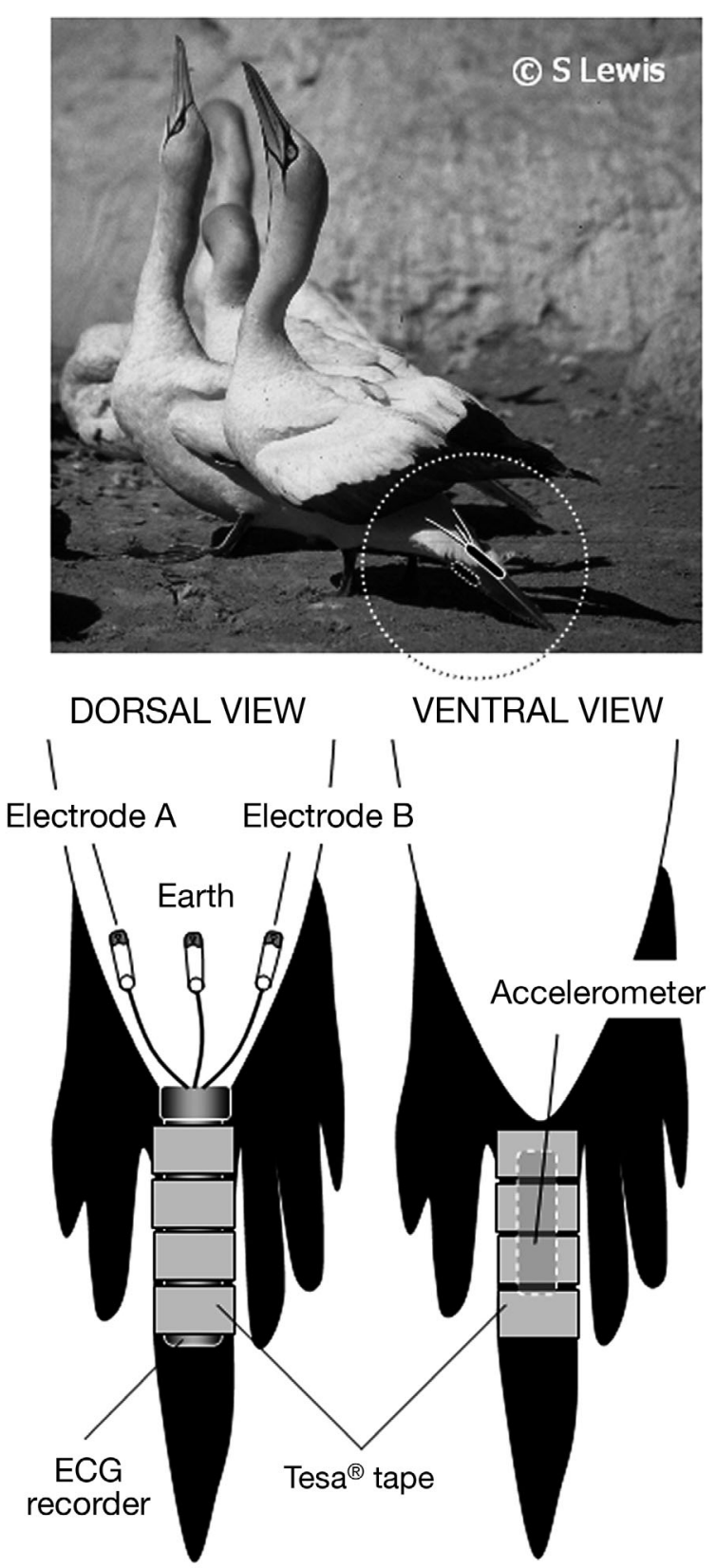

Fig. 1. Morus capensis. Point of attachment of the electrocardiogram (ECG) loggers and accelerometers. The ECG logger was placed on the dorsal face of the retrices, while the accelerometer was attached to the ventral face 


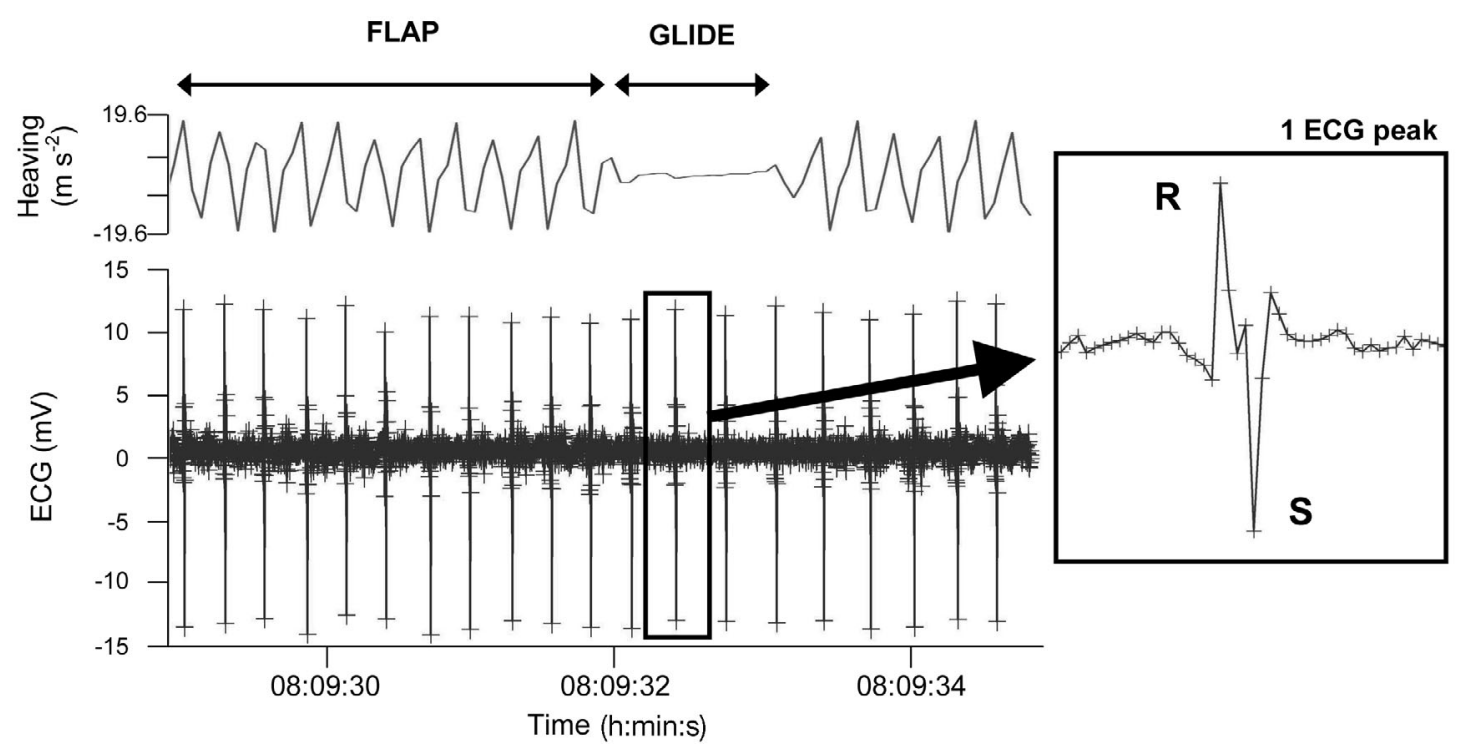

Fig. 2. Morus capensis. Typical signal recorded by accelerometers during heaving acceleration (top signal) and by ECG loggers (bottom signal). Flapping flight is visible on the heaving signal as an oscillating pattern, while the absence of such pattern reflects gliding activity. Details of an ECG peak are presented in the inset, with the clear R and S peaks

sentation of limb beating in several studies using similar loggers on a variety of bird species (e.g. RopertCoudert et al. 2004, Weimerskirch et al. 2005). The determination of the wing beat was conducted using the heaving acceleration signal (the most sensitive to undulation in the birds' bodies resulting from wing beats).

ECG data were smoothed using a binomial function. The resulting smoothed signal was subtracted from the original data to remove the noise caused by muscular movements. ECG peaks during flight were, therefore, clearly identified (Fig. 2, bottom axis). The number of ECG peaks during a given activity and the duration of each activity were determined automatically using a purpose-written program (Igor Pro v. 5.01, Wavemetrics) and heart rate ( $\mathrm{HR}_{i}$ in beats per minute, bpm) was calculated as:

$$
\mathrm{HR}=N / d
$$

where $N$ is the total number of ECG peaks (counted from one ECG peak to another) over time interval $d$ in minutes.

In 2002, we concurrently instrumented Cape gannets at Malagas and Lambert's Bay with similar accelerometers and GPS (global positioning system) devices (cf. Grémillet et al. 2004). The analysis of the flight tracks and the acceleration signals revealed that birds preferentially adopt a looping route in which the inbound and outbound flights correspond to long (>15 min) flight sessions where birds alternated flapping and gliding (see Ropert-Coudert et al. 2004 for details) with very few plunges or stops. Following this, we defined travelling flights in the present study as the uninterrupted flight bout that directly follows departure from the colony (the outbound flight), any commuting flight phases $>15$ min between diving bouts, and return to the colony (the inbound flight). In contrast, all flight activity associated with dive bouts (i.e. when dives occurred within 5 to 10 min of each other), as well as the 2 min flight phase preceding the first dive of a bout or an isolated dive (Nelson 1978), is hereafter referred to as 'foraging flight'. HR was calculated for each flight phase. HR data during take-off phases (as well as during the first 2 to $3 \mathrm{~s}$ of the dive) could not be isolated due to signal noise resulting from extensive muscular activity at these times. Consequently, our values for foraging flights will be underestimates, since the high cost of take-off (Weimerskirch et al. 2000) is not included in the calculation. None the less, take-offs and diving only represent $1.9 \pm 0.4 \%$ of the time spent at sea (calculated on 10 Cape gannets equipped with similar accelerometers in 2002; Y. Ropert-Coudert unpubl. data), so we believe this underestimation is not excessive.

To determine the extent to which wing-flapping activity influenced HR, we measured HR over 1 min flight periods, selected throughout the foraging trips of gannets. These HR were then regressed against the total number of flaps and their average amplitude, as recorded by the accelerometers during this $1 \mathrm{~min}$ period. Each 1 min flight session was separated from the next one by at least 2 min.

Trends between variables were highlighted using residual maximum-likelihood (REML) analyses (Pat- 
terson \& Thompson 1971), with bird identity as a random effect to control for pseudo-replication. All values are reported as mean $( \pm 1$ SD). The statistical threshold was taken at 0.05. Statistical tests were conducted using JMP (SAS Institute, v. 5.1.1J), Systat (SAS Institute, v. 10) and StatView (SAS Institute, v. 5.0J).

\section{RESULTS}

Of 8 Morus capensis equipped with ECG loggers, 1 did not go to sea. Following deployment, this bird was released near its nest and started to perform neckstretching display, before exchanging the egg with its partner. It consequently sat on its nest, while the noninstrumented partner left after a few minutes. It is likely that we misidentified the birds at the time of capture and actually equipped the bird that was returning from a foraging trip. This logger was removed after $2 \mathrm{~h}$. Another logger stopped recording after $1 \mathrm{~h}$, before the bird left the colony. For the remaining 6 birds, ECG data were recorded for the full ca. $8 \mathrm{~h}$ memory limit of the loggers (acceleration data were recorded for approximately $4.5 \mathrm{~d}$ ). Among these 6 individuals, ECG data were recorded for the full duration of the foraging trips of 2 birds, which underwent short $(<8 \mathrm{~h})$ foraging trips, while the 4 other birds went to sea for 2 or more days. For these 4 birds, the $8 \mathrm{~h}$ of HR data logged accounted for $87 \pm 13 \%$ of the first day at sea (i.e. from the first take-off to the last flight session before darkness).

The HR of the Cape gannet that stayed on its nest for $2 \mathrm{~h}(08: 46$ to $10: 46 \mathrm{~h}$, local time) was $197.4 \pm 7.5 \mathrm{bpm}$. Cape gannets standing on land (away from their nests), prior to departure for foraging, and Cape gannets floating at the sea surface (at least 10 min after the cessation of any diving or flying activity) had HR of $215.4 \pm 20.3$ and $208.9 \pm 10.7 \mathrm{bpm}$, respectively $(\mathrm{n}=6$ birds). HR on land and at sea were averaged over five 1 min periods selected from the period recorded on land and at sea, respectively.

Typical acceleration signals during the flap-glide alternating flight mode and the corresponding ECG peaks are shown in Fig. 2. Visually, we could see a substantial inter- and intra-individual variability in the HR values (intra-individual variability is exemplified in Fig. 3). In Fig. 3, the HR during active flapping phases in most instances did not seem to differ from that observed during the subsequent gliding phase. In con-

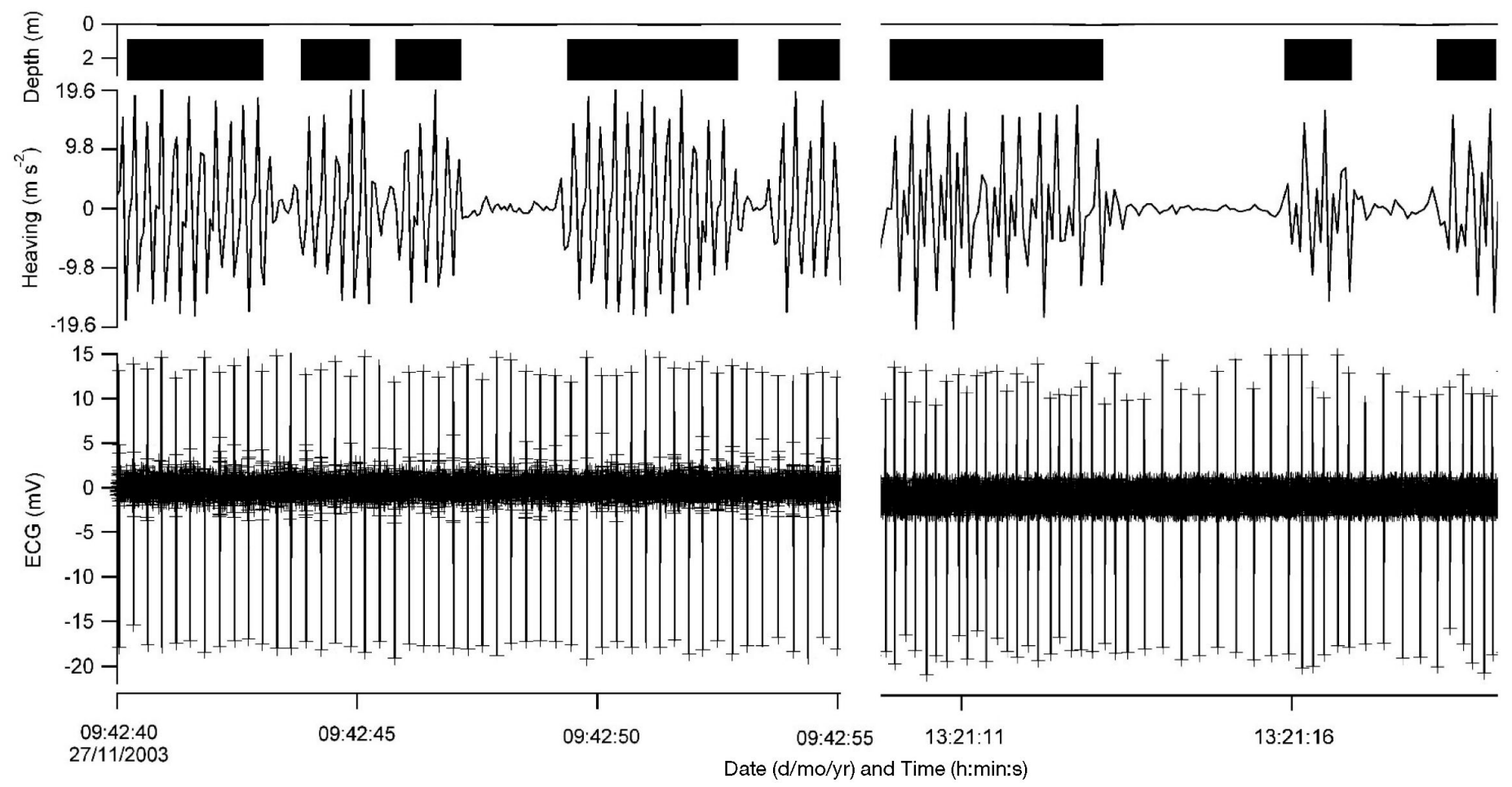

Fig. 3. Morus capensis. Depth (top trace), heaving acceleration (middle trace) and ECG (bottom trace). On the left part of the graph, the difference in the delay between 2 ECG peaks during flap (horizontal black bars) and glide is undetectable to the naked eye, while later in the trip (right side of the graph) the delay between ECG peaks during flap flight is almost twice that during gliding 
trast, there were periods when the HR while flapping was ca. twice the gliding HR (Fig. 3). However, these periods of elevated HR while flapping were not specifically linked to intense diving activity, and they were not observed at the end of protracted flight sequences. In flight, Cape gannets flapped their wings on average $66.4 \pm 4.0 \%$ of the time, but this proportion was $76.8 \pm$ 7.6 (range: 68.4 to $86.9 \%$ ) during foraging flight, and $61.1 \pm 12.1$ (range: 37.4 to $71.8 \%$ ) during travelling flight. Despite substantial flapping activity during foraging, the HR of gannets during foraging flight $(228.4 \pm 17.7 \mathrm{bpm})$ was significantly lower (REML, $\left.F_{1,5}=94.0, \mathrm{p}<0.001\right)$ than that during travelling flight $(236.4 \pm 38.2 \mathrm{bpm})$, when flight speeds are faster (44 to $50 \mathrm{~km} \mathrm{~h}^{-1}$; Grémillet et al. 2004). In addition, HR during flapping flight was significantly higher (REML, $F_{1,5}=$ 1901.0, $\mathrm{p}<0.001$ ) than that during gliding phases (see individual trends in Table 1). The interaction between flight phase (travelling vs. foraging) and flight type (flapping vs. gliding) was also significant $\left(F_{1,5}=8.0, \mathrm{p}=\right.$ 0.005). Consideration of all data taken together gave a mean HR during flapping flight (the mean of meansTable 1) of $250.4 \pm 46.3 \mathrm{bpm}$, while the equivalent value for gliding flight was $217.2 \pm 16.8 \mathrm{bpm}$ (Table 1 ). Overall, the lowest (183.9 bpm) and highest (417.8 bpm) HR were recorded in 2 different birds during a glide and a flapping phase, respectively, both during travelling flight.

Although relatively modest $(13 \%)$, the decrease in HR when birds ceased flapping was almost instantaneous, irrespective of the duration of the subsequent glide phase (Fig. 4A). However, there was considerable inter-individual variability, with the difference in HR between the 2 activities ranging from 12 to $42 \%$ ( $\mathrm{n}=6$ birds). The situation was similar when birds started flapping after a glide phase, with a virtually

Table 1. Morus capensis. Heart rates (HR, beats per minute, number of events in parentheses) of individual Cape gannets recorded during the flap and glide phases when the birds were engaged in flight activity, irrespective of the phase of the foraging trip (Overall HR) and whether engaged in foraging or travelling flight (see 'Materials and methods' for definition)

\begin{tabular}{|lllllll}
\hline $\begin{array}{l}\text { Bird } \\
\text { no. }\end{array}$ & \multicolumn{2}{c}{ Flap } & \multicolumn{1}{c}{ Glide } & \multicolumn{2}{c}{ Forall HR } & \multicolumn{2}{c}{ Travelling HR } \\
\hline B15 & $210.7 \pm 17.7(615)$ & $192.5 \pm 9.0(613)$ & $214.9 \pm 19.7(400)$ & $193.5 \pm 9.8(367)$ & $202.8 \pm 9.0(215)$ & $191.1 \pm 7.3(246)$ \\
B16 & $257.1 \pm 58.1(1746)$ & $227.6 \pm 20.6(1820)$ & $254.4 \pm 39.4(208)$ & $213.9 \pm 16.1(203)$ & $257.5 \pm 60.1(1538)$ & $229.4 \pm 20.4(1817)$ \\
B18 & $239.7 \pm 16.4(2201)$ & $228.7 \pm 6.2(2289)$ & $244.3 \pm 12.2(59)$ & $224.3 \pm 5.6(62)$ & $239.6 \pm 16.5(2142)$ & $228.8 \pm 6.2(2227)$ \\
B23 & $210.3 \pm 18.9(3137)$ & $199.8 \pm 12.2(3131)$ & $220.3 \pm 30.0(198)$ & $198.1 \pm 19.5(189)$ & $209.7 \pm 17.7(2939)$ & $199.9 \pm 11.5(2942)$ \\
B25 & $248.3 \pm 35.3(2120)$ & $221.7 \pm 9.8(2015)$ & $254.2 \pm 28.2(150)$ & $218.1 \pm 8.9(126)$ & $247.9 \pm 35.8(1970)$ & $221.9 \pm 9.8(1889)$ \\
B27 & $366.3 \pm 65.3(1684)$ & $232.6 \pm 24.6(1692)$ & $289.6 \pm 70.5(166)$ & $209.9 \pm 13.7(161)$ & $374.7 \pm 59.0(1518)$ & $235.0 \pm 24.3(1531)$ \\
\end{tabular}

A

B

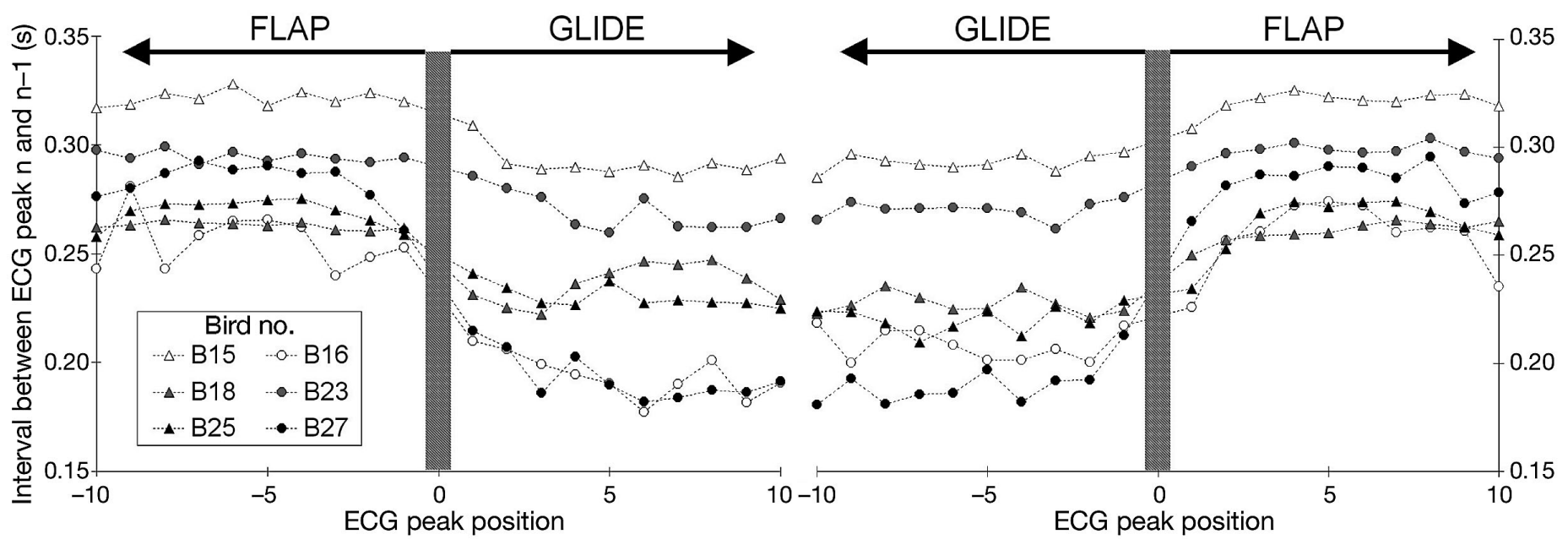

Fig. 4. Morus capensis. Interval between 2 successive ECG peaks ( $\mathrm{n}-[\mathrm{n}-1])$ around the transition point between flap and glide phases, denoted by the value 0 on the $x$-axis 


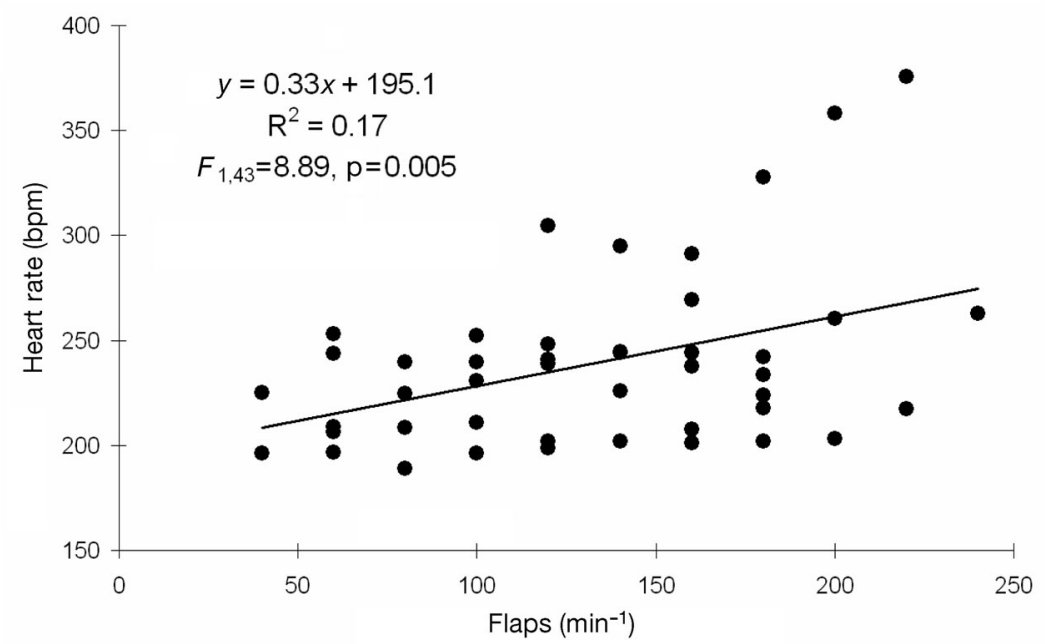

Fig. 5. Morus capensis. Relationship between the number of wing flaps and heart rate, calculated over $1 \mathrm{~min}$ periods selected throughout the foraging trip. Each point shows a mean from an individual gannet within the flap rate bracket specified

instantaneous increase in HR and substantial interindividual variability in the magnitude of that increase (Fig. 4B).

The HR increased with the duration of the flapping phase $\left(F_{1,5}=11.3, \mathrm{p}<0.001\right)$ and decreased with the duration of the gliding phase $\left(F_{1,5}=101.2, \mathrm{p}<0.001\right)$. However, the duration of the flap or glide phase explained only a minor proportion of the variability of the HR values, as indicated by the extremely small coefficient of determination $\left(\mathrm{R}^{2}<0.1\right.$ for both flap and glide phases). The multiple regression between HR of birds (recorded over 1 min flight sessions) and the number and average amplitude of the wing flaps (over these flights) indicated that these variables were strongly correlated $\left(\mathrm{R}^{2}=0.60\right)$. The REML test revealed that the effect of the number of wing flaps was significant $\left(F_{1,5}=4.0, \mathrm{p}=0.046\right)$, although the coefficient of determination was small (Fig. 5), but that the effect of the average amplitude of flaps was not $\left(F_{1,5}=1.9, \mathrm{p}=\right.$ $0.17)$.

\section{DISCUSSION}

Although we could not monitor entire foraging trips, we were able to cover a substantial percentage of the first day spent at sea by the instrumented gannets Morus capensis. Our data provide the first measurement of HR levels in free-ranging gannets. Furthermore, the use of externally attached ECG recorders allowed us to determine the HR of birds with high accuracy (each peak of ECG being individually detected; cf. Enstipp et al. 2001) and to relate it to their instantaneous activity.

\section{Resting heart rate}

It is generally accepted that HR at rest decreases with increasing body mass in vertebrates. In birds, the relationship has been described by:

$$
f_{\mathrm{h}}=155.8 \times M^{-0.23}
$$

where $M$ is the body mass (in $\mathrm{kg}$ ) (Schmidt-Nielsen 1984). Cape gannets weigh 2.5 to $3 \mathrm{~kg}$ (Rand 1960), and so have a predicted resting HR of around $120 \mathrm{bpm}$. This is approximately 0.6 times the HR of the single bird that spent an extended time at its nest or that recorded from other birds on land and resting at the sea surface. This suggests either that Cape gannets do not conform to the relationship or that, despite the absence of dynamic acceleration recorded during the nest, land and sea phases, the birds were not really resting sensu Schmidt-Nielsen (1984): high HR values on land can be attributed to stress from handling (despite all precautions), stress related to nest defence and antagonistic behaviour from neighbours (as suggested by Adams et al. 1991). Thermoregulation may also have played a role, especially since temperature can be very high in the colony (up to $32-37^{\circ} \mathrm{C}$ in December in both colonies, www.weathersa.co.za/; Hochscheid et al. 2002). Resting metabolic rates at sea may well be higher than those on land, which would tend to increase HR (assuming that there is a linear relationship between the two, but see below), because aquatic birds as diverse as tufted ducks Aythya fuligula and penguins Spheniscidae have higher metabolic rates in water than in air (e.g. Culik \& Wilson 1991 and references therein) by a factor of about 2.3. In addition, high post-dive HR at sea may be related to energy-expensive processes associated with prey ingestion such as the costs of heating cold food (Wilson \& Culik 1991) and specific dynamic action, i.e. the increased energy expenditure associated with digestion, assimilation and biosynthesis (Secor \& Diamond 2000). Thus, in the absence of other information, and given the scatter around the relationship between resting HR and body mass in birds, we assume that our measured HR from gannets purported to be resting are unusually high because the birds were not genuinely resting.

\section{Evolution of heart rate with activity}

Cape gannets in the present study exhibited only a $10 \%$ difference between the mean HR of birds rest- 
ing at sea and that during flapping flight. In addition, there was virtually no difference between the HR of birds gliding and that of those resting at sea. These results are similar to the values recorded by Weimerskirch et al. (2000), who found little change between HR of wandering albatrosses during flight and that of those resting on water (both being around 1.4 times the resting rate). In wandering albatross, the highest HR were found for take-off and walking on land, reaching 2 and 4 times the resting rates, respectively (Weimerskirch et al. 2000). However, albatrosses are known to be efficient gliders that can cover long distances relying on gliding flight mode only. Correspondingly, Weimerskirch et al. (2000) and Shaffer et al. (2001) noted HR in flying wandering albatrosses Diomedea exulans that were just 1.4 times those of resting rates on land. In contrast, Cape gannets spend about $40 \%$ of their time at sea actually flying (Adams \& Klages 1999, Ropert-Coudert et al. 2004), and we found that about $72 \%$ of flying time is spent actively flapping, a value that accords well with the $79 \%$ reported by Ropert-Coudert et al. (2004). The gannets' gliding phases averaged $2.3 \mathrm{~s}$ (SD: $0.75 \mathrm{~s}$, maximum duration: $32 \mathrm{~s}$ ) before being interrupted by renewed flapping. In other words, Cape gannets flap less often than cormorants, but more often than albatrosses and closely related boobies. Although HR dropped immediately following the cessation of flapping, the difference between HR measured during flapping and those during gliding flights only amounts to about $20 \%$.

We purport that the data recorded were not spurious, since we took the uttermost precautions to ensure the validity of the data recorded by both accelerometers and ECG recorders. As mentioned above, identification of wing beats in the signals recorded by the same accelerometers as those used in the present study has been verified in several seabird species (e.g. RopertCoudert et al. 2004, Weimerskirch et al. 2005). The reliability of our HR recording system has already been discussed at length in 'Materials and methods'. Thus, the concomitant analysis of the wing beat-to-wing beat and ECG-to-ECG peak, together with the extremely fine scale of the measurements (16 data points s ${ }^{-1}$ and 500 points $\mathrm{s}^{-1}$ for the acceleration and ECG data, respectively), allowed us to verify the small difference between the HR during flapping and gliding flight.

Nonetheless, the minimal differences reported here (gliding vs. flapping and resting at sea vs. flapping) are surprising. After all, sustained flapping flight necessitates substantial power output (Pennycuick 1987), being accompanied by tachycardia associated with vasodilation of the pectoral muscles (Butler \& Bishop 2000). In accordance with this, Grémillet et al. (2005) documented that the HR of great cormorants Phalacro- corax carbo during sustained flight is 3 times higher than that at rest on land.

As we do not know the shape of the relationship between HR and metabolic rate, we cannot report the exact cost of flight. However, the small differences in HR between activities authorises us to speculate about the possible link between these 2 currencies and how changes in HR observed in our study may relate to estimated costs and metabolic rates as reported in other studies. Indeed, there seems to be a discrepancy between the small HR differences we observed in our study and the high FMR (metabolic rate of adults at sea $=6.5 \times$ the basal metabolic rate on land; Adams et al. 1991) estimated through doubly labelled water and attributed to the intensive use of flapping flight in foraging Cape gannets. This suggests that HR and metabolic rate do not correlate linearly. An exponential relationship would mean that even a small difference in HR would relate to a large change in the metabolic rate and, although the absence of rigorous calibration using respirometry in tandem with HR recording does not allow us to test this supposition conclusively, we note that some studies have demonstrated that the gradient of HR against energy expenditure varies according to activity (Froget et al. 2002, Ward et al. 2002, McPhee et al. 2003). Energy expenditure is assumed to be directly related to $\mathrm{HR}$, because $\mathrm{HR}$ and oxygen consumption $\left(V \mathrm{O}_{2}\right)$ are related following Fick's law:

$$
V \mathrm{O}_{2}=\mathrm{HR} \times V_{\mathrm{s}} \times\left(\mathrm{CaO}_{2}-\mathrm{CvO}_{2}\right)
$$

where $V_{\mathrm{s}} \mathrm{CaO}_{2}$ and $\mathrm{CvO}_{2}$ are the stroke volume and the arterial and the venous blood oxygen concentration, respectively (Nolet et al. 1992), which are either constant or vary systematically with effort (Butler 1991). One possibility that our results could suggest is that cardio-vascular adjustments in gannets during flapping flights may take place. It is, for instance, increasingly recognised that stroke volume could vary as much as does HR (cf. Froget et al. 2002, Ward et al. 2002, McPhee et al. 2003). Similarly, the difference in oxygen content between arterial and venous blood may change with activity. The relationship may be further complicated by variability according to a number of factors including individuals (Hüppop 1987), dietary state (Fahlman et al. 2005) and even type of exercise; penguins, for example, have a different gradient in the relationship between $\mathrm{HR}$ and $\mathrm{VO}_{2}$ for variable power outputs when swimming compared to walking (Bevan et al. 2002, Green et al. 2002, 2003). Finally, inter-individual foraging success (unfortunately difficult to assess in free-ranging Cape gannets) could markedly influence the apparent relationship between HR and metabolic rate due to the increased energy demands 
necessary to heat cold prey (cf. above), tending to blur relationships between wing flap frequency and metabolic rate. In other words, conversion from HR to metabolic rate should be taken with great care.

Our study suggests that Cape gannets are adapted to both powered and gliding flight, with little difference in HR between the 2 activities. Potential causes for this strategy include the foraging techniques of the birds and wind patterns within their foraging areas. Cape gannets forage by plunge-diving in the Benguela upwelling ecosystem. They are coastal seabirds, foraging within $100 \mathrm{~km}$ of colonies (e.g. Grémillet et al. 2004), not long-distance travellers such as most albatrosses. Their foraging bouts alternate between short travel phases, during which gliding can be employed, and phases of active prey searching and plungediving, which require powered flight. They are also constrained by coastal topography and cannot readily structure their foraging trips to avoid headwinds as do albatrosses breeding at oceanic islands (Weimerskirch et al. 2000). Birds from Malgas and Bird Islands forage within a narrow corridor along the Atlantic coast of South Africa, with prevailing south-westerly winds. They benefit from tail winds during parts of their voyages, but also have to manoeuvre and make use of powered flight when flying into the wind. This scenario is supported by flight speed measurements of foraging Cape gannets tracked by GPS (Grémillet et al. 2004).

In many other bird species, such as boobies (Weimerskirch et al. 2005), pelicans (Weimerskirch et al. 2001) and gulls (Meyers \& Mathias 1997), the amount of flapping during flight is dictated by wind, thermal and topographic conditions (cf. Furness \& Bryant 1996). Studies of the effort associated with flight activity (measured through HR as a proxy) as a function of the local environmental conditions are particularly relevant in the current context of global warming, where changes in the wind patterns and prey dispersal will condition the areas and times of year that species can exploit.

Acknowledgements. This study was approved by the University of Cape Town's Animal Ethics Committee and was conducted under permits from Cape Nature Conservation (Lambert's Bay) and South African National Parks (Malgas Island). It was supported financially by a joint France-South Africa research project administered by the French CNRS and the National Research Foundation. Additional financial support was provided by the Japan Society for Promotion of Science. We thank the wardens at Bird Island and Lambert's Bay for their help in the field, R. E. H. Müllers, R. H. Navarro and A. and B. Butterblock in South Africa, and Prof. Y. Naito, M. Kuroki and K. Kobayashi in Japan. P. J. Butler, G. L. Kooyman and M. E. Enstipp provided useful comments on an earlier version of this manuscript.

\section{LITERATURE CITED}

Adams NJ, Klages NTW (1999) Foraging effort and prey choice in Cape gannets. S Afr J Mar Sci 21:157-163

Adams N, Abrams R, Siegfried W, Nagy K, Kaplan I (1991) Energy expenditure and food consumption by breeding Cape gannets Morus capensis. Mar Ecol Prog Ser 70:1-9

Ballance LT (1995) Flight energetics of free-ranging redfooted boobies (Sula sula). Physiol Zool 68:887-914

Bevan RM, Butler PJ, Woakes AJ, Prince PA (1995) The energy expenditure of free-ranging black-browed albatrosses. Phil Trans R Soc Lond B 350:119-131

Bevan RM, Butler PJ, Woakes AJ, Boyd IL (2002) The energetics of gentoo penguins, Pygoscelis papua, during the breeding season. Funct Ecol 16:175-190

Birt-Friesen V, Montevecchi W, Cairns D, Macko S (1989) Activity-specific metabolic rates of free-living northern gannets and other seabirds. Ecology 70:357-367

Butler PJ (1991) Exercise in birds. J Exp Biol 160:233-262

Butler PJ, Bishop CM (2000) Flight. In: Whittow GC (ed) Sturkie's avian physiology. Academic Press, Oxford

Butler PJ, Woakes AJ (1979) Changes in heart rate and respiratory frequency during natural behaviour of ducks, with particular reference to diving. J Exp Biol 79:283-300

Croll DA, Gaston AJ, Burger AE, Konof D (1992) Foraging behavior and physiological adaptation for diving in thickbilled murres. Ecology 73:344-356

Culik BM, Wilson RP (1991) Energetics of underwater swimming in Adélie penguins (Pygoscelis adeliae). J Comp Physiol 161:285-291

Enstipp MR, Andrews RD, Jones DR (2001) The effects of depth on the cardiac and behavioural responses of double-crested cormorants (Phalacrocorax auritus) during voluntary diving. J Exp Biol 204:4081-4092

Fahlman A, Handrich Y, Woakes AJ, Bost CA, Holder RL, Duchamp C, Butler PJ (2005) The effect of fasting on the $V \mathrm{O}_{2}$ and $f_{\mathrm{H}}$ relationship in king penguins Aptenodytes patagonicus. Am J Physiol Reg I 289:670-679

Froget G, Handrich Y, Le Maho Y, Rouanet JL, Woakes AJ, Butler PJ (2002) The heart rate/oxygen consumption relationship during cold exposure of the king penguin: a comparison with that during exercise. J Exp Biol 205: $2511-2517$

Furness RW, Bryant DM (1996) Effect of wind on field metabolic rates of breeding northern fulmars. Ecology 77 : 1181-1188

Green JA, Butler PJ, Woakes AJ, Boyd IL, Holder R (2001) Heart rate and rate of oxygen consumption of exercising macaroni penguins. J Exp Biol 204:673-684

Green JA, Butler PJ, Woakes AJ, Boyd IL (2002) Energy requirements of female macaroni penguins breeding at South Georgia. Funct Ecol 16:671-681

Green JA, Butler PJ, Woakes AJ, Boyd IL (2003) Energetics of diving in macaroni penguins. J Exp Biol 206:43-57

Grémillet D, Wilson RP (1999) A life in the fast lane: energetics and foraging strategies of the great cormorant. Behav Ecol 10:516-524

Grémillet D, Dell'Omo G, Ryan PG, Peters G, Ropert-Coudert Y, Weeks SJ (2004) Offshore diplomacy, or how seabirds mitigate intra-specific competition: a case study based on GPS tracking of Cape gannets from neighbouring colonies. Mar Ecol Prog Ser 268:265-279

Grémillet D, Kuntz G, Woakes AJ, Gilbert C, Robin JP, Le Maho Y, Butler PJ (2005) Year-round recordings of behavioural and physiological parameters reveal the survival strategy of a poorly insulated diving endotherm during the Arctic winter. J Exp Biol 208:4231-4241 
Hochscheid S, Grémillet D, Wanless S, du Plessis MA (2002) Black and white under the south African sun: Are juvenile Cape gannets heat stressed? J Therm Biol 27:325-332

Hüppop O (1987) Der Einfluss von Wachstum, Thermoregulation und Verhalten auf den Energiehaushalt der Silbermöwe. PhD thesis, University of Hamburg

Jouventin P, Weimerskirch H (1990) Satellite-tracking of wandering albatrosses. Nature 343:746-748

Kuroki M, Kato A, Hayama S, Naito Y (1999) Preliminary report of new method for ECG measurement of exercising birds. Polar Biosci 12:40-46

McPhee JM, Rosen DAS, Andrews RD, Trites AW (2003) Predicting metabolic rate from heart rate in juvenile Steller sea lions Eumetopias jubatus. J Exp Biol 206:1941-1951

Meyers RA, Mathias E (1997) Anatomy and histochemistry of spread-wing posture in birds. 2. Gliding flight in the California gull, Larus californicus: a paradox of fast fibers and posture. J Morphol 233:237-247

Nagy KA, Girard IA, Brown TK (1999) Energetics of freeranging mammals, reptiles, and birds. Annu Rev Nutr 19: 247-277

Nelson B (1978) The Sulidae: gannets and boobies. Oxford University Press, Berkhamsted

Nolet BA, Butler PJ, Masman D, Woakes AJ (1992) Estimation of daily energy expenditure from heart rate and doubly labelled water in exercising geese. Physiol Zool 65: 1188-1216

Norberg UM (1986) Flying, gliding, and soaring. In: Hildebrand M, Bramble DM, Liem KF, Wake DB (eds) Functional vertebrate morphology. Belknap Press of Harvard University, Cambridge, MA

Patterson HD, Thompson R (1971) Recovery of inter-block information when block sizes are unequal. Biometrika 58: 545-554

Pennycuick CJ (1982) The flight of petrels and albatrosses (Procellariiformes), observed in South Georgia and its vicinity. Phil Trans R Soc Lond B 300:75-106

Pennycuick CJ (1987) Flight of seabirds. In: Croxall JP (ed) Seabirds. Feeding ecology and role in marine ecosystems. Cambridge University Press, Cambridge

Pennycuick CJ (1989) Bird flight performance: a practical calculation manual. Oxford University Press, Oxford

Pennycuick CJ (2002) Gust soaring as a basis for the flight of petrels and albatrosses (Procellariiformes). Avian Sci 2: $1-12$

Phillips RA, Xavier JC, Croxall JP (2003) Effects of satellite transmitters on albatrosses and petrels. Auk 120: 1082-1090

Rand RW (1960) The biology of guano-producing birds, Chap 3. The distribution, abundance and feeding habits of the cormorants Phalacrocoracidae off the southwestern coast of the Cape province. Investigational Report 42, Division

Editorial responsibility: Howard Browman (Associate Editorin-Chief), Storebø, Norway of Fisheries, Department of Commerce and Industries, Cape Town

Ropert-Coudert Y, Wilson RP (2005) Trends and perspectives in animal-attached remote-sensing. Frontiers Ecol Environ 3:437-444

Ropert-Coudert Y, Grémillet D, Kato A, Ryan PG, Naito Y, Le Maho Y (2004) A fine-scale time budget of Cape gannets provides insights into their foraging strategies. Anim Behav 67:985-992

Schmidt-Nielsen K (1984) Scaling. Why is animal size so important? Cambridge University Press, Cambridge

Secor SM, Diamond J (2000) Evolution of regulatory responses to feeding in snakes. Physiol Biochem Zool 73: 123-141

Shaffer SA, Costa DA, Weimerskirch H (2001) Behavioural factors affecting foraging effort of breeding wandering albatrosses. J Anim Ecol 70:864-874

Storch S, Grémillet D, Culik BM (1999) The telltale heart: a non invasive method to determine the energy expenditure of incubating great cormorants Phalacrocorax carbo carbo. Ardea 87:207-215

Ward S, Bishop CM, Woakes AJ, Butler PJ (2002) Heart rate and the rate of oxygen consumption of flying and walking barnacle geese (Branta leucopsis) and bar-headed geese (Anser indicus). J Exp Biol 205:3347-3356

Weimerskirch H, Guionnet T, Martin J, Shaffer S, Costa DP (2000) Fast and fuel efficient? Optimal use of wind by flying albatrosses. Proc R Soc Lond B 267:1869-1874

Weimerskirch $\mathrm{H}$, Martin J, Clerquin $\mathrm{Y}$, Alexandre $\mathrm{P}$, Jiraskova S (2001) Energy saving in flight formation. Nature 413:697-698

Weimerskirch H, Shaffer SA, Mabille G, Martin J, Boutard O, Rouanet JL (2002) Heart rate and energy expenditure of incubating wandering albatrosses: basal levels, natural variation, and the effects of human disturbance. J Exp Biol 205:475-483

Weimerskirch H, Le Corre M, Ropert-Coudert Y, Kato A, Marsac F (2005) The three dimensional flight of red-footed boobies: adaptations to foraging in a tropical environment. Proc R Soc Lond B 272:53-61

Wilson RP, Culik BM (1991) The cost of a hot meal: facultative specific dynamic action may ensure temperature homeostasis in post-ingestive endotherms. Comp Biochem Physiol A 100:151-154

Wilson RP, Pütz K, Peters G, Culik B, Scolaro JA, Charrassin JB, Ropert-Coudert Y (1997) Long-term attachment of transmitting and recording devices to penguins and other seabirds. Wildl Soc Bull 25:101-106

Yamamoto M (2001) The role of the autonomic nervous system in the regulation of circulation in great cormorant. $\mathrm{PhD}$ thesis, The Graduate University for Advanced Studies, Yokohama (in Japanese)

Submitted: February 15, 2006; Accepted: May 24, 2006

Proofs received from author(s): December 12, 2006 